\title{
MOBILIDADE HUMANA E DESASTRES AMBIENTAIS: A GESTÃO URBANA EM ÁREAS DE RISCO
}

\author{
Érica Tavares da Silva Rocha ${ }^{1}$
}

\section{RESUMO}

Objetivo: A relação entre a questão urbana e ambiental tem produzido conflitos em todo o espaço urbano brasileiro. O objetivo deste artigo é analisar os processos de mobilidade humana no contexto dos desastres a mbientais, considerando o histórico de desastres relacionados à água em Campos dos Goytacazes/RJ e o pa pel da gestão urbana no processo de remoção de famílias, sob a construção do discurso de que estão em áreas de risco.

Referencial teórico: A pesquisa se orienta teoricamente por uma abordagem sociológica dos desastres a mbientais e por uma perspectiva da construção social do risco, que influencia tanto a gestão urbana quanto as formas de enfrentamento por parte da população.

Método: A metodologia utilizada foi a análise secundária de dados sobre ocorrência de desastres no município e a realização de uma pesquisa de survey domiciliar em uma área afetada por inundações na cidade, através de entrevista estruturada.

Resultados e conclusão: Os resultados mostram a ocorrência de uma expressiva mobilidade residencial na área, promovida tanto pelas questões ambientais quanto por interesses políticos e econômicos nas disputas por apropriação do espaço a liados a mecanismos autoritários que levaram à remoção de famílias por meio de uma gestão urbana seletiva e fragmentada.

Implicações da pesquisa: O estudo aponta que é preciso promover instâncias de articulação política que contemplem a participação da comunidade nos processos decisórios e a implementação de políticas integradas nessas áreas.

Originalidade/valor: $O$ estudo reforça, ainda, que as práticas de gestão socioambiental precisam considerar a perspectiva dos atingidos por desastres ambientais.

Palavras-chave: Mobilidade humana. Desastres a mbientais. Inundações. Gestão urbana.

RGSA adota a Licença de Atribuição CC BY do Creative Commons (https://creativecommons.org/licenses/by/4.0/). (c) (i)

\footnotetext{
${ }^{1}$ Doutorado em Planejamento Urbano e Regional pelo Instituto de Pesquisa e Planejamento Urbano e Regiona 1 , Rio de Janeiro. Professor Adjunto da Universidade Federal Fluminense, Rio de Janeiro (Brasil). Email: ericatavr@gmail.com Orcid: https://orcid.org/0000-0002-2427-5602
} 


\title{
HUMAN MOBILITY AND ENVIRONMENTAL DISASTERS: URBAN MANAGEMENT IN RISK AREAS
}

\begin{abstract}
Purpose: The relationship between urban and environmental issues has produced conflicts throughout the Brazilian urban space. This paper analyzes the processes of human mobility in environmental disasters, considering the history of water-related disasters in Campos dos Goytacazes municipality, Rio de Janeiro State, Brazil, and the role of urban management in the process of removal of families under the discourse that they a re in risk areas.
\end{abstract}

Theoretical framework: The research is theoretically guided by a sociological approach to environmental disasters and by a perspective of the social construction of risk, which influences both urban manage ment and the ways of dealing with it by the population.

Method/design/approach: The methodology used was the secondary analysis of data on the occurrence of disasters in the municipality and a household survey in an area affected by floods in the city through a structured interview.

Results and conclusion: The results show expressive residential mobility in the area, promoted both by environmental issues and political and economic interests in the disputes over the appropriation of space, as well as by authoritarian mechanisms that led to the removal of families through selective and fragmented urban management.

Research implications: The study points out the need to promote political articulation that contemplates community participation in decision-making processes and the implementation of integrated policies in these areas.

Originality/value: It also reinforces that social and environmental management practices should consider the view of those affected by environmentaldisasters.

Keywords: Human mobility. Environmentaldisa sters. Floods. Urban management.

\section{INTRODUÇÃO}

O processo de ocupação e apropriação do espaço pelos grupos sociais é fundamental para compreender a relação entre sociedade e ambiente no contexto urbano. No caso brasileiro, as grandes cidades e metrópoles se formaram como resultado de um complexo processo de mudanças sociais, econômicas, políticas e ambientais que alteraram profundamente a dinâmica da população, sua localização e suas condições de reprodução social. O acelerado processo de urbanização levou à constituição de cidades que apresentaram e ainda apresentam enormes contradições, uma vez que muitas famílias tiveram que estabelecer suas residências em áreas sujeitas a alagamentos, inundações, deslizamentos etc., pelas dificuldades sociais, econômicas e de acesso a adequadas condições de moradia. Boa parte das demais cidades desse complexo sistema urbano acompanhou essa dinâmica contraditória ao reproduzir a constituição de uma cidade desigual — que não distribui, de forma igualitária, os riscos sociais e ambientais — aliada a um planejamento também contraditório e, por vezes, excludente. É nesse sentido que os desastres ambientais devem ser estudados considerando as dimensões históricas de cada lugar.

Vale ressaltar que boa parte dos estudos sobre dinâmica ambiental e mobilidade humana em contextos de desastres ambientais consideram essa relação em escalas nacionais e internacionais, como o impacto das mudanças climáticas globais sobre as migrações 
internacionais. Igualmente, há estudos na escala nacional que analisam, por exemplo, os conflitos ambientais gerados pela implementação de grandes projetos de investimento como os projetos e intervenções ligados à construção de complexos industriais, portos e usinas hidrelétricas - , que também provocam deslocamentos forçados e alteram as condições de permanência para os estabelecidos em determinado lugar. Da mesma forma, tem sido lamentavelmente comum e necessária a referência, por parte dos estudiosos, a casos emblemáticos como os desastres ambientais provocados por rompimento de barragens, exemplo de Mariana e Brumadinho, que, além das mortes e de uma série de danos humanos e materiais, causaram o deslocamento de muitas famílias do seu lugar original de residência. Afora esses desastres, há muitos outros presentes no cotidiano das cidades que ora podem ser mais impactantes — como os deslizamentos em Niterói, em 2010, ou as chuvas na região serrana, em 2011 — , ora podem não ter um caráter trágico ligado a mortes imediatas, mas trazem muitas consequências para o cotidiano de famílias afetadas, como as inundações, objeto deste artigo. Portanto, considera-se importante contemplar essa escala de análise e intervenções.

Muitos desses eventos acabam provocando processos de mobilidade humana na própria escala interna da cidade. Ao não passarem por uma gestão urbana que contemple as dimensões sociais e ambientais dos processos humanos, tais movimentos podem se dar de maneira forçada por meio das remoções realizadas pelo poder público, por exemplo. Portanto, o objetivo deste artigo é analisar a relação entre a mobilidade humana e a ocorrência de desastres ambientais na cidade, questionando o papel da gestão urbana nessa relação. Para tanto, levantam-se o histórico de desastres relacionados à água em um município do Norte do estado do Rio de Janeiro, as recentes intervenções do poder público municipal e, principalmente, as experiências de moradores em áreas consideradas de risco. Os desastres ambientais na cidade serão apreendidos através da ocorrência de inundações; a mobilidade humana, por meio da mobilidade residencial e dos deslocamentos forçados; e a gestão urbana, por políticas urbanas nessas áreas, no caso do município de Campos dos Goytacazes.

A metodologia utilizada baseou-se em levantamento de dados secundários, a partir de fontes oficiais, sobre a ocorrência de desastres no município. Apesar do porte populacional e da extensão territorial, o município sempre foi considerado uma cidade média do interior fluminense exercendo uma polaridade histórica no contexto regional. A partir da década de 2000, em razão, sobretudo, das atividades petrolíferas, industriais e logístico-portuárias na região, Campos também reafirma sua inserção na dinâmica econômica global, sendo levantadas, inclusive, discussões sobre a sua inserção e a de outros municípios da região na dinâmica da metropolização brasileira.

Em que pese a polaridade econômica e política de épocas passadas, o município apresenta muitas desigualdades socioespaciais e ambientais. A elas soma-se um histórico de desastres relacionados à água — como alagamentos e inundações — acompanhado de intervenções do poder público municipal na remoção de famílias, sob a construção do discurso de que estão em áreas de risco, levando a refletir sobre os processos de mobilidade humana nesse contexto. Este trabalho questiona em que medida a mudança de residência é potencializada efetivamente pelas condições ambientais do lugar e pelos aspectos sociais da comunidade ou por uma gestão urbana mais aliada a interesses privados nas disputas pelo espaço. Para tratar sobre isso neste artigo, também são utilizadas informações secundárias sobre ocorrência de eventos no município de estudo, assim como dados provenientes de uma pesquisa de survey domiciliar, com aplicação de questionários no recorte territorial definido como áreas afetadas por inundações em uma localidade do referido município, expressão dessa cond ição histórica. 
O artigo está estruturado em mais quatro seções, além desta introdução. A próxima seção trata justamente sobre a mobilidade humana a partir da relação sociedade e ambiente no contexto urbano. Também é problematizado o papel do planejamento no histórico processo de ocupação e apropriação do espaço nas cidades brasileiras. A terceira seção traz essa abordagem como lente de análise para os processos de ocupação do espaço em Campos dos Goytacazes, município do qual foram levantadas as informações sobre ocorrências de desastres e áreas de risco e onde se concentrou o trabalho de campo da pesquisa. A quarta seção traz os aspectos metodológicos da pesquisa. A quinta e última seção considera a influência da população sobre o ambiente e vice-versa, por meio do levantamento de dados e a partir da ótica dos próprios sujeitos, analisando os mecanismos que operam no contexto de desastres ambientais (como as inundações) sobre os processos de mobilidade humana (como as mudanças de residência em uma localidade do município de estudo), em especial a influência da gestão urbana.

\section{MOBILIDADE HUMANA, DESASTRES AMBIENTAIS E A NOÇÃO DE "R ISCO" NA POLÍTICA URBANA}

O acelerado processo de urbanização brasileiro trouxe uma série de desigualdades sociais, econômicas e espaciais para a configuração do espaço urbano. Durante o rápido crescimento populacional das cidades latino-americanas nas décadas de 1960 e 1970 e sendo impulsionada pelo modelo de desenvolvimento adotado, a mobilidade espacial, apreendida principalmente através das migrações e, depois, por meio dos movimentos pendulares, sempre foi uma das estratégias adotadas pela população em busca de melhorar suas condições de reprodução social. No Brasil, o período de intensas migrações internas esteve associado ao avanço do processo de urbanização. Segundo Brandão (2007, p. 170), no Brasil, "massas populacionais imensas buscaram novos lugares geográficos (promovendo uma das maiores mobilidades espaciais do mundo, uma verdadeira transumância) e novos loci de status social".

Nesse processo, foi possível observar a constituição de áreas "não urbanizadas" nas cidades, onde boa parte dessa população construiu suas moradias ocupando terrenos de forma ilegal ou semilegal, com exposição a expressivos riscos ambientais, como deslizamentos, inundações e alagamentos. O padrão de urbanização desorganizado, marcado pelo laissez faire urbano (Ribeiro, 2008) - que envolve uma ausência articulada do poder público nessas áreas e uma gestão tolerante com as formas de apropriação do espaço —, contribuiu para a expansão dos riscos ambientais que geralmente acometem as populações mais pobres e vulneráveis tanto em áreas urbanas quanto rurais.

Maricato (2002) também coloca que, como parte das regras do jogo, a ocupação de terras urbanas sempre foi tolerada, já que o Estado não intervinha em certos espaços, ou seja, a ausência de políticas coordenadas fazia parte da própria gestão urbana. Muitas vezes, não era a norma jurídica, mas a lei de mercado que se impunha, demonstrando que, nas áreas desvalorizadas ou inviáveis para o mercado (beira de córregos, reservas e áreas de proteção ambiental, por exemplo), a lei "pode(ria)" ser transgredida. O direito à invasão seria até admitido, mas não o direito à cidade. Assim, o critério definid or acaba sendo o do mercado ou o da localização (Maricato, 2002, p. 161). Nesse processo de disputas por apropriação do espaço, aliado ao crescimento populacional, à expansão urbana e a uma gestão seletiva dos espaços da cidade, foram produzidos custos ambientais e sociais "ocultos, dificilmente visíveis no início, mas desastrosos para a população e o poder público a longo prazo" (Acselrad, 2009, p. 12). 
É por isso que o processo de urbanização e a forma como os distintos grupos sociais ocuparam a cidade é fundamental para compreender a relação entre os desastres ambientais e os processos de mobilidade humana na escala da cidade, que muitas vezes são engendrados pela política urbana implementada, como será tratado nos resultados do estudo empírico em seção posterior. Vários autores abordam os mecanismos sociais, políticos, econômicos e ambientais operantes nos processos de ocupação e apropriação do espaço afirmando que a cidade desigual no Brasil está na origem da concepção de "desastre como um processo socialmente construído" (Carmo, 2014, p. 4), uma relação integrante do processo de construção social, pois foi produzida a partir da ação da sociedade que produz e distribui, de forma desigual, os riscos ambientais e sociais (Deschamps, 2008).

Ou seja, mesmo que em muitos momentos a situação de desastre seja desencadeada por algum fenômeno "natural" (gera lmente a ssocia do com o ciclo hidrológico, como chuva ou seca), esta situação se configura em desastre porque, por um lado, atinge populações humanas, ameaçando a vida de pessoas e seus bens materiais e imateriais, e, por outro, é resultante de processos de interação entre a dinâmica populacional e a dinâmica ambiental, concretizadas em uma forma específica, historicamente construída, de ocupação do espaço (Carmo, 2014,p.4).

Carmo (2014) também afirma que as cidades brasileiras manifestam tais desigualdades a partir de dois tipos de assentamento humano: os assentamentos precários e os assentamentos urbanos "normais". Em linhas gerais, a diferença entre esses tipos será a perspectiva de "permanência": o primeiro remete às favelas e áreas de vulnerabilidade, que teriam um status provisório, mesmo a população estando lá há décadas; o segundo tipo, embora bastante heterogêneo, teria um status de permanência maior. É por isso que a possibilidade de "remoção" para os assentamentos precários sempre é acionada como possível solução nas situações de desastre (Carmo, 2014, p. 5). Valencio (2009) também discorre sobre essa relação considerando os termos "área carente" e "área de risco", que passam a atuar na gestão urbana em áreas com ocorrências de inundações, por exemplo.

O termo 'área de risco' corrobora com os significados do termo precedente, mas acresce componentes do ambiente natural na equação a fim de problematizar o direito de morar como algo situado a lém da esfera sócio-política acima considerada . (...) Tudo se passa, entretanto, como se a inserção de moradias em solos propensos a tais eventos fosse um risco auto-imposto à vida, uma convivência arbitrária dos mora dores do local com a meaças natura is, o que converteria sua territoria lização em algo inadmissível, ilegítimo (Valencio, 2009 p. 35).

Vários estudos têm mostrado que é geralmente nessas áreas invisibilizadas que os desastres acontecem (Valencio, 2012; Siqueira, Valencio, Siena \& Malagodi, 2015). Ademais, a forma como o poder público atua ou deixa de atuar nesses espaços pode agravar tal situação. Por isso, concebemos que os desastres não têm origem apenas em eventos físicos e naturais, são também resultantes, muitas vezes, da forma como se estruturaram (ou não) os espaços ao longo de muito tempo. Sendo assim, embora haja diferentes concepções, de forma geral, os desastres são vistos como fenômenos sociais no campo das ciências humanas e sociais. Como afirma Quarantelli (2015, p. 37):

De uma certa forma, podemos dizer que o paradigma básico implícito na área dos desastres é aceitável (embora não incontestável). O paradigma atual envolve uma série de noções inter-relacionadas, mas duas das noções mais fundamentais são as seguintes: (1) os desastres são fenômenos socia is inerentemente, e (2) a origem dos desastres se encontra na estrutura social ou no sistema social.

Isso significa que os grupos sociais residentes nesses locais vivenciam significativas contradições. Como trata Marandola Jr. (2014, p. 43), o advento das cidades e das 
concentrações populacionais traz em si uma nova concepção de habitar. A princípio, habitar nas cidades teria relação com uma diminuição dos riscos e da insegurança. Mesmo que sempre haja alguma incerteza, na cidade, seria possível aproveitar as condições da concentração de bens, recursos e oportunidades oferecidas - inclusive a potencialidade do conhecimento científico e tecnológico de apoiar a gestão urbana a fim de intervir e controlar os eventos da natureza. Entretanto, nas áreas que tiveram uma urbanização precária, não há apenas incerteza, mas um risco associado a essa ocupação e aos desastres. "Em primeiro lugar, em vez de encará-los como incertos, agora eles poderiam ser compreendidos e previstos, no tempo e no espaço. A incerteza é substituída pelo risco, com suas probabilidades, fatores causais e propostas de gestão para lidar com os desastres" (Marandola Jr., 2014, p. 43). É preciso ressaltar que essa concepção de risco não pode ocultar a perspectiva dos desastres como processos socialmente construídos (Quarantelli, 2015, pp. 3940).

Sendo assim, os estudos sobre mobilidade humana e ambiente envolvem considerar os processos de ocupação do espaço e o uso dos recursos naturais pela população, assim como as condições humanas nas quais esses processos se dão para diferentes grupos sociais. Para além da concepção de migração, a mobilidade humana no espaço é encarada, dessa forma, como um conceito que remete a características sociais, econômicas, políticas e ambientais das pessoas, dos lugares e processos. Tal concepção imprime "a exigência de uma nova situação histórica na qual as relações entre homem e natureza são qualitativamente diferentes" (Hogan, 2005, p. 326).

A ocupação desordenada e sem planejamento por parte do estado, aliada a um quadro de restrições de acesso à moradia adequada, faz com que muitos grupos sociais se movam para espaços "impróprios" para moradia e essa mobilidade da população traz consequências para o ambiente. No caso dos desastres ambientais urbanos, a relação pode se dar na via oposta, e a mobilidade pode ser encarada também como elemento que decorre das mudanças ambientais. É comum após os eventos — ou mesmo a partir da exposição a situações de perigo - iniciar-se algum tipo de intervenção que acarrete processos de mobilidade, trazendo mudanças expressivas para a comunidade afetada. Segundo Urry (2007), o mundo móvel contemporâneo parece ser caracterizado por impressionantes novos riscos, perigos e restrições para pessoas, lugares e ambientes, ao mesmo tempo que pode representar novas oportunidades para as arriscadas vidas móveis (Urry, 2007).

Para Marandola Jr. e Dal Gallo (2010, p. 407), a mobilidade pode ser entendida como um "fenômeno vivido em diferentes escalas espaço-temporais, mas que possui, do ponto de vista fenomenológico, uma mesma essência constitutiva". Isso implica considerar que, mesmo com escalas, motivos e sentidos distintos, há algo de essencial no ser que se desloca e em sua experiência. Podemos inferir que todo movimento envolve desenraizamento, descontinuidades e rupturas, que alteram as trajetórias individuais e/ou familiares. Abrange a necessidade de refazer os laços de pertencimento, pois "migrar é ser obrigado a desenvolver outros tipos de territorialidade, dando um salto em direção ao desconhecido" (Marandola Jr. \& Dal Gallo, 2010, p. 410). Embora os autores acionem a categoria migração em sentido mais amplo e na escala nacional/internacional, tais apontamentos se aplicam também à mobilidade humana na cidade. Além disso, quando o deslocamento é desencadeado pelo próprio poder público como mecanismo de gestão dos conflitos urbanos, sociais e ambientais, o processo se torna ainda mais complexo.

A partir de estudos em escala internacional, Arnall (2018) e Marter-Kenyon (2020) analisam criticamente os processos de realocação planejada da população liderada pelo estado, que tem avançado como uma forma de adaptação às mudanças climáticas. Esse movimento é chamado de climate-related relocation (CRR), que teria como objetivo afastar 
as pessoas de áreas ambientalmente perigosas; o movimento seria entendido como um mecanismo para redução da exposição ao perigo. Nesse movimento, os autores diferenciam os processos de reassentamento e redistribuição da população, assim como problematizam a concepção de voluntaried ade e participação nos processos por parte da população.

A ocorrência de eventos naturais adversos diante de condições sociais, econômicas e políticas frágeis da população acaba gerando os desastres ambientais que também afetam a sociedade e a mobilidade humana. Em muitos casos, a intervenção efetiva do estado só ocorre no período pós-desastre, gerando novos processos de mobilidade - muitas vezes na forma de deslocamentos forçados. A remoção de famílias das "áreas de risco" para outras áreas da cidade geralmente envolve uma administração técnica dos riscos, que considera padrões de situações de risco, e não a diversidade das realid ades e dos comportamentos sociais (Guivant, 1998). A partir de Marter-Kenyon (2020), podemos afirmar que esse tipo de intervenção se enquadra na perspectiva da mudança ambiental, migração e adaptação ou environmental migration and adaptation (EMA). Tal fato contribui para um discurso dominante promulgado por elites políticas internacionais, qual seja, o de que a realocação deve ser um esforço de último recurso, porém estritamente necessário para preservar vidas e garantir a segurança humana.

Nessa linha, a vulnerabilidade é vista como um produto dos eventos extremos, e as soluções são pensadas no plano normativo-gerencial e no nível individual/comunitário. Ainda pode ocorrer mediante mecanismos autoritários e sem instâncias de participação coletiva, trazendo rupturas nos vínculos sociais, enfraquecimento dos sentimentos de pertencimento e muitas dificuldades de adaptação aos lugares de destino. Portanto, pode revelar uma gestão urbana que desconsidera as condições ambientais do lugar e os aspectos sociais da comunidade, ao contrário do proposto por autores mais alinhados à abordagem da ecologia política sobre a importância da política e do projeto de cidade considerar quem ganha e quem perde nos processos de mudança socioecológica (Swyngedouw \& Heynen, 2003; Acselrad, 2009).

A abordagem histórico-política desestabiliza a perspectiva anterior, e o discurso associado mostra que "a história, a política, o poder e o discurso influenciam o significado da adaptação ao clima, os tipos das intervenções permitidas e os resultados variados daí resultantes" (Marter-Kenyon, 2020, p. 165). A construção social do risco se alinha a essa última abordagem, em que a emergência da realocação da população reside em contingências históricas, discursivas, na construção social do risco e na (bio)política do meio ambiente e do desenvolvimento. Ao problematizarem o próprio conhecimento sobre os riscos questionando, principalmente, a perspectiva técnica, Douglas e Wildavsky (2012) também colocam que a questão sobre "que tipos de riscos são aceitáveis para que tipos de pessoas" é sempre uma questão política. Sendo assim, mudar a territorialidade dos distintos grupos sociais em função de riscos apresenta uma dimensão política.

Mas a localização dos grupos sociais e as trajetórias/caminhos percorridos no cotidiano demonstram as atividades sedimentadas de uma comunidade que, muitas vezes, se estendem por gerações. Já as mudanças de localização e o redirecionamento de uma trajetória em razão dos riscos, ou mesmo sua eliminação - como pode ocorrer a partir de um desastre ambiental - poderão ser vistos como um atentado contra aquela comunidade e suas memórias coletivas, contra as formas de habitar e mover-se em um dado lugar (Urry, 2007, p. 32).

Essa problemática se dá em diversas escalas, desde deslocamentos internacionais em razão de mudanças climáticas, passando por migrações internas nos países, até deslocamentos no espaço intraurbano, este último geralmente analisado sob o termo mobilidade residencial. 
É nesse contexto que a lógica inscrita nesse deslocamento precisa ser analisada em sua complexidade, já que há diversos mecanismos que atuam sobre os processos de mobilidade.

O estudo das lógicas de mobilidade espacial envolve uma análise complexa que deve levar em conta tanto as perspectivas de escolha por parte dos sujeitos quanto as perspectivas de constrangimento ao qual podem ser submetidos (Silva, 2012). Além disso, é preciso considerar as lógicas de imobilidade que operam nas condições de reprodução social dos indivíduos e famílias.

Em última instância, embora haja uma decisão ao empreender um deslocamento no espaço - o que sempre faz parecer ter sido um movimento por escolha —, não se podem ocultar os reais motivos para tal empreitada, ainda mais em contextos de desastres ambientais. "Deslocamentos compulsórios, restrições à circulação nos falam de um território que não é nem espaço abstrato da racionalidade, nem mera manifestação da estrutura; eles nos contam a história de um território que é lugar do conflito e do exercício do poder” (Vainer, 2000, p. 828).

É nessa perspectiva que os estudos sobre mobilidade humana relacionados a desastres ambientais se tornam importantes, não tomando a mobilidade apenas como consequência, mas como elemento constituinte do processo de desastre, seja pelos afetados considerados desabrigados e desalojados temporariamente, seja por aqueles que mudam permanentemente de suas residências, ou mesmo que são removidos pelo poder público. Geralmente, concebese que "onde a mobilidade é forçada, isso pode gerar privação social e exclusão" (Urry, 2007, pp. 8-9), o que ocorre quando as famílias são constrangidas a mover-se. Mas também para aqueles que, por qualquer razão, são negadas as possibilidades de mobilidade, normalmente também operam múltiplas formas de exclusão. Portanto, para além de um fenômeno individual, a mobilidade é um processo social, inscrita na lógica de ocupação do espaço e das intervenções públicas na cidade.

Nesse sentido, a mobilidade humana que se dá no espaço urbano também precisa ser estudada do ponto de vista dos sujeitos, num olhar mais qualitativo sobre o fenômeno, sobretudo em contexto de desastres ambientais na cidade, de modo que esse olhar contribua para a gestão urbana nas áreas consideradas de risco.

\section{PROCESSOS DE OCUPAÇÃO DO ESPAÇO E IMPACTOS AMBIENTAIS EM CAMPOS}

As relações empíricas e conceituais apontadas anteriormente sobre as questões urbanas e ambientais a partir dos desastres e dos processos de mobilidade humana encontram lugar em diversas cidades brasileiras. Na cidade de Campos dos Goytacazes, na Região Norte do estado do Rio de Janeiro, a ocupação e apropriação do espaço urbano também apresenta estreita relação com a dinâmica ambiental.

O processo de urbanização em Campos dos Goytacazes se acentuou em torno da década de 1950/60, em meio a um contexto de crise da indústria sucroalcooleira regional no Norte Fluminense. Boa parte das desigualdades sociais e espaciais que o município acumulou ao longo de muitos anos é creditada a esse processo (Cruz, 2003).

A região perdeu sua posição de grande produtora na agroindústria do açúcar, entre outros motivos, por não ter acompanhado as transformações tecnológicas modernizantes introduzidas no setor no plano nacional. O estabelecimento da indústria petrolífera na região, por volta dos anos 1970/1980, apesar de ter gerado novas faces para o desenvolvimento econômico regional, não acarretou transformações que viessem a suplantar as desigualdades intrarregionais. Até porque boa parte da dinâmica engendrada por esse setor mobilizou 
recursos, população e capital de outras áreas do País e até do exterior, e não conectou em escala ampla a população já residente na região nesse processo.

Aliado ao quadro econômico nacional e estadual do início dos anos 1980, “os municípios da região também enfrentavam uma estagnação econômica, queda da produtividade, desemprego e até aumento da pobreza e deslocamentos do campo para as periferias das cidades da região" (Piquet, 2010, p. 80). Cruz (2003) também indica que muitos bairros urbanos foram constituídos nesse contexto, o que "gerou um contingente de milhares de boias-frias, expulsos do campo para a cidade, vivendo em condições precárias de vida e de renda" (Cruz, 2003, p. 297).

Inserido na dinâmica econômica e financeira global, o Norte Fluminense também experimentou uma série de transformações econômicas no século XXI, que estiveram e estão pautadas pela atuação da indústria petrolífera e pelo desenvolvimento das atividades logísticoportuárias e industriais (Cruz \& Terra, 2020). Embora a primeira tenha como principal sede das empresas o município de Macaé e as últimas estejam concentrando-se no complexo portuário do Açu, em São João da Barra, a polaridade histórica do município de Campos e seu porte populacional de cidade mais consolidada - com acesso mais ampliado a serviços médicos e educacionais, oferta de bens e outros serviços mais especializados - fazem com que a cidade também seja impactada pelo processo de globalização e financeirização da economia, assim como sua inserção e a de outros municípios da Região Norte e dos Lagos no processo de metropolização (IBGE, 2016; Lencioni, 2015; Bartholomeu, 2018). A população estimada de Campos, em 2020, foi de 511.168 habitantes segund o dados do IBGE (2020) - o maior município em porte populacional fora da região metropolitana no estado do Rio de Janeiro e o maior em extensão no território fluminense.

Os estudos sobre os impactos ambientais do processo de urbanização-metropolização também tornam-se pertinentes não apenas nas metrópoles consolidadas, mas nas áreas sobre as quais tal processo se estende (Leopoldo, 2018). É muito comum observar que a incorporação de novos espaços na dinâmica da urbanização pode igualmente acarretar a reprodução de processos socioespaciais: há uma difusão da lógica dos grandes empreendimentos, dos condomínios fechados e do consumo padronizado e direcionado cada vez mais articulados ao mercado de capitais e à financeirização imobiliária, que trazem impactos consideráveis sobre a relação população e ambiente no contexto urbano. Exemplos dessa situação foram analisados por Torres, Ramos e Sanches (2018) ao tratar sobre os casos de ampliação do Porto de São Sebastião e da implantação de um condomínio logístico em Paranapiacaba na macrometrópole paulista. Tais casos retratam a questão dos conflitos ambientais e como estes estão relacionados a uma nova escala de planejamento, que cada vez mais ultrapassa o limite político-administrativo municipal ou mesmo regional.

Como visto, a ocupação e apropriação do espaço urbano, muitas vezes "desord enada", incidiu diretamente sobre o meio ambiente e as condições de reprodução social da população dos bairros mais periféricos da cidade de Campos, suscitando diversas limitações de caráter ambiental, social e econômico. Nessa nova dinâmica econômica globalizada, no caso do Norte Fluminense, potencializada pela atuação das indústrias extrativas no setor petrolífero e atividades portuárias na região, tais condições podem acirrar-se — vide o exemplo de desapropriações, deslocamentos forçados e reapropriação do espaço pelo capital financeiroimobiliário-urbano que também acompanham a lógica da urbanização e financeirização aliada às implicações particulares nos espaços de extração de recursos naturais (Arboleda, 2015).

Assim como em outras cidades brasileiras, a localização dos grupos sociais no espaço da cidade de Campos foi e continua sendo marcada por mecanismos de segmentação e segregação socioespaciais, que afetam, sobretudo, a população mais pobre, muitas vezes restando, para este grupo, as áreas mais degradadas, em encostas e beiras de rios e lagoas, 
com condições ambientais desfavoráveis e sem infraestrutura para constituírem seus espaços de moradia (Tavares \& Firmo, 2018).

\section{MÉTODO}

O método para a análise aqui apresentada considerou um breve levantamento de dados secundários e informações provenientes de uma pesquisa de survey domiciliar. $\mathrm{O}$ levantamento de dados sobre os atingidos por desastres se deu por meio do Sistema Integrado de Informações sobre Desastres (S2ID), ligado ao Ministério do Desenvolvimento Regional, que "integra diversos produtos da Secretaria Nacional de Proteção e Defesa Civil - SEDEC, com o objetivo de qualificar e dar transparência à gestão de riscos e desastres no B rasil, por meio da informatização de processos e disponibilização de informações sistematizadas dessa gestão" (Brasil, 2019). Também foram utilizados dados disponíveis para o município de Campos dos Goytacazes no site do Observatório de Migrações Forçadas (Instituto Igarapé, 2019), que compila e produz mapeamentos de dados sobre pessoas deslocadas em processos relacionados a desastres ambientais, projetos de desenvolvimento e presença de refugiados. $\mathrm{O}$ Observatório de Migrações Forçadas traz a descrição e análise de uma série de casos emblemáticos, como os projetos de desenvolvimento para a construção de usinas hidrelétricas em Belo Monte (PA), Irapé (MG), Lajeado (TO) e Itá (RS); também faz a utilização de dados do próprio S2ID.

Além disso, também foi feita uma análise primária de dados através de pesquisa de survey com aplicação de questionários por meio de entrevistas nas áreas definidas como afetadas por inund ação na localidade de Ururaí em Campos dos Goytacazes. A escolha desse lugar se deve ao seu histórico de inundações e à atuação do poder público no local. A definição das áreas baseou-se em observações de campo na localidade e em estudos anteriores realizados (Siqueira \& Malagodi, 2013; Siqueira et al., 2015). Foram aplicados 232 questionários após percorrer todos os domicílios do recorte delimitado. Embora o objetivo geral dessa pesquisa fosse mais amplo, o presente artigo traz somente aspectos ligados aos processos de mobilidade humana no contexto de desastres ambientais, como as inundações, considerando não só a atuação do poder público sob o discurso do risco, mas também a percepção dos sujeitos que vivenciam tais situações numa área de considerável mobilidade residencial. Estudos como esses têm sido realizados a partir da abordagem da construção social do risco, visando relativizar as percepções e o discurso do estado, do saber técnico e dos peritos com as percepções e representações sociais dos atingidos, como realizado por Beltramino (2018), Soares \& Cruz (2019), Fragoso \& Silva (2019), Quiñonez, Saavedra, Cevallos \& Jiménez (2020).

\section{RESULTADOS E DISCUSSÕES}

Nesta seção, pretende-se explorar empiricamente a relação existente entre os processos de mobilidade humana e a ocorrência de desastres ambientais no contexto urbano e como se dá esse processo a partir da política urbana em áreas consideradas de risco. Para tanto, considera-se um histórico recente de desastres relacionados à água no município de Campos dos Goytacazes/RJ - sobretudo através da ocorrência de inundações - e as consequentes intervenções do poder público municipal na remoção de famílias sob a construção do discurso de que estão em áreas de risco, o que influenciou a mobilidade residencial na cidade.

\begin{tabular}{|l|l|l|l|l|l|}
\hline Rev. Gest. Soc. Ambient. & São Paulo (SP) & v.15 & p.01-21 & e02767 & 2021. \\
\hline
\end{tabular} 


\subsection{A mobilidade humana e os desastres ambientais em Campos}

O histórico de ocupação do espaço na cidade de Campos trouxe consequências para a forma como os grupos sociais, sobretudo entre os mais pobres, se apropriam do espaço até os dias atuais. Ao buscar informações sobre pessoas afetadas por desastres na cidade, nota-se através dos dados da tabela 1 que, de 2003 a 2012, segundo informações do Observatório de Migrações Forçadas, há uma ocorrência constante de eventos na cidade que afetam o cotidiano dos moradores, sejam aqueles mais comuns como enxurradas, tempestades e alagamentos, sejam eventos mais adversos, como as inundações.

Tabela 1 - Pessoas deslocad as em eventos ligados a desastres - Campos dos Goytacazes 2003 a 2012

\begin{tabular}{|c|c|c|c|c|c|c|c|c|c|c|}
\hline Eventos & 2003 & 2004 & 2005 & 2006 & 2007 & 2008 & 2009 & 2010 & 2011 & 2012 \\
\hline Enxurrada & 60 & & & 2.650 & & 450 & 120 & & & \\
\hline Tempestades* & & 83 & & & & 350 & & 154 & & \\
\hline Inundação & & 34 & 225 & & & 22.662 & 420 & 195 & 3.209 & 769 \\
\hline Alagamentos & & & & & & 216 & & & & \\
\hline Total & 60 & 117 & 225 & 2.650 & - & 23.678 & 540 & 349 & 3.209 & 769 \\
\hline
\end{tabular}

*Tempestade Local/Convectiva - Vendaval.

Fonte: Observatório de Migrações Forçadas (Instituto Igarapé, 2019)

Devido a inund ações, por meio do registro, podemos observar a expressiva quantidade de casos em 2008, em seguida, em 2011. A grande enchente de 2008 é a que mais se apresenta na memória dos moradores, como relatado por eles, sobretudo os que foram diretamente afetados por terem sido deslocados de suas residências. Segundo dados da defesa civil (S2ID/SEDEC), e corroborando com o quantitativo apresentado na tabela 1, foi grande o número de afetados tanto na área urbana quanto na área rural. As localidades de Ururaí e Tapera, consideradas na área urbana, foram as mais atingidas, o que acarretou consideráveis danos humanos (pelo expressivo número de desalojados e desabrigados) e materiais (edificações danificadas como residências, órgãos públicos, estradas, pavimentação de vias urbanas etc.).

Os números retratados na tabela 1 levam em conta pessoas desalojadas e desabrigadas, podendo haver uma variação no tempo em que foram afetadas; mesmo assim, envolve um tipo de mobilidade humana temporária que pode desencadear processos de mobilidade mais permanente, em virtude da recorrência de tais eventos. Segundo Menezes (2012), as migrações múltiplas refazem as concepções de origem e destino. No caso da mobilidade humana na cidade, também poderíamos falar de mobilidades múltiplas, em que a população se desloca diversas vezes em busca de garantir sua reprodução social; não há uma origem e nem um destino específico determinado temporal e espacialmente. É nesse sentido que os estudos sobre mobilidade humana e desastres ambientais podem se dar em diversas escalas, contextos e sentidos do movimento.

Realmente, a mobilidade temporária (como a condição de desalojado ou desabrigado) transformou-se em uma mobilidade mais permanente para alguns moradores das áreas afetadas, devido à opção por uma gestão dos desastres baseada em processos de remoção. $\mathrm{Ou}$ seja, o processo de mobilidade impulsionado por elementos do ambiente e por um discurso autoritário pode gerar problemas para uma efetiva apropriação do espaço, com enfraquecimento dos vínculos sociais e espaciais e do sentimento de pertencimento por parte da população envolvida. 


\subsection{Mobilidade humana e inundações: contradições da política urbana}

Em Campos dos Goytacazes, a localidade de Ururaí é uma das que apresenta esses problemas ligados ao processo de ocupação do espaço e os impactos no ambiente. O bairro está localizado ao sul do município, cortado pela BR 101 em direção à capital do Rio de Janeiro. Sua população era de aproximadamente 8.800 habitantes em 2010, com cerca de 2.640 residências segundo dados do IBGE (2010). A ocupação do espaço se deu muito próxima ao Rio Ururaí — que circunda parte do bairro - e esteve bastante atrelada à inserção do município de Campos na agroindústria açucareira nacional no século passado, sendo a presença da Usina Cupim um elemento fundamental para o povoamento da localidade.

As condições sociais e econômicas de muitas famílias residentes no bairro, sobretudo aquelas que residem mais próximas ao rio, são relativamente precárias e experimentam acesso a serviços, moradia e infraestrutura urbana em situação bastante desigual em relação a áreas mais centrais da cidade, e até mesmo em comparação a outros espaços do próprio bairro, em áreas mais elevadas. Ururaí apresenta um histórico de desastres relacionados à água. Para os moradores entrevistados na pesquisa, a maior inundação ocorreu em 2008 (conforme registro na tabela 1) e é a que mais está presente na memória dos residentes. Mas "ainda que os eventos desastrosos de maior magnitude ocorram com baixa periodicidade, verifica-se que outros de menor intensidade acontecem com maior frequência" (Almeida \& Leite, 2017, p. 2).

Em razão dos problemas urbanos e de infraestrutura em várias localidades do município, a prefeitura implementou o Programa Bairro Legal, uma política pública urbana que tinha por objetivo a melhoria das condições de infraestrutura urbana de algumas áreas, considerando ainda aspectos urbanísticos e fundiários dos vários loteamentos existentes. Tais ações também contaram com obras de drenagem de águas pluviais, de rede de abastecimento de água e tratamento de esgoto, pavimentação de ruas e mobilidade urbana, entre outros aspectos. Alguns bairros da cidade foram contemplados com essa política, tais como: Ururaí, Penha, Parque Eldorado, Novo Eldorado. Observou-se que o investimento em algumas condições de infraestrutura foi realizado, porém, ao mesmo tempo, vários moradores relatam problemas em relação à execução das obras, partes não concluídas e serviços malfeitos, como na própria localid ade de Ururaí.

A outra política urbana de grande impacto na localidade foi a remoção de famílias para conjuntos habitacionais. Em finais dos anos 2000, a Prefeitura de Campos lançou um grande programa habitacional denominado Morar Feliz, cujo objetivo era fornecer cerca de 10 mil moradias às famílias residentes em áreas considerad as de risco, como beira de rios, lagoas, rodovias e ferrovias, ou seja, áreas com histórico de desastres relacionados à água, como inundações. Aqui, vemos uma clara relação entre a dimensão ambiental relacionada aos desastres e à noção de risco com a política urbana no que se refere à habitação.

Apesar da disponibilização das casas para muitas famílias que realmente precisavam de melhores condições de moradia, o programa refletiu vários dos problemas já indicados amplamente na história dos programas habitacionais no Brasil e na cidade de Campos (Azevedo, Thimóteo \& Arruda, 2013; Mendes, 2015). Os projetos urbanísticos foram insuficientes e, a despeito de algumas pessoas terem tido acesso a uma moradia melhor, não houve um planejamento adequado para a condução da política habitacional nem um estudo prévio tanto das áreas de origem quanto das áreas de destino, muito menos das condições às quais essas famílias estariam submetidas, revelando uma gestão fragmentada e a setorialização das políticas sociais. Soares e Fragoso (2019) também revelam que os riscos ambientais em Belém estão relacionados a problemas de infraestrutura e aos impactos de grandes projetos urbanísticos. Assim, as inundações têm origem em processos históricos de 
ocupação do solo e manifestam as desigualdades socioespaciais, que se mantêm mesmo após grandes investimentos em drenagem e saneamento.

Com isso, muitas famílias foram removidas para lugares distantes dos bairros de origem; não houve mecanismos de participação da população na concepção e execução do processo, ocorrendo, assim, uma mistura de populações de diferentes áreas da cidade (inclusive membros de divergentes facções do crime, segundo relatos dos moradores), dificuldades de deslocamento e acesso a trabalho e educação por parte da população removida, entre outros aspectos.

Acrescente-se a esse quadro a contradição de que, em várias áreas rotuladas como "de risco", seguiu-se à remoção de famílias pobres um processo de forte atuação do capital imobiliário exatamente nas áreas próximas.

Portanto, Mendes (2015) aponta como a dimensão do risco teve um importante impacto na gestão urbana, visando mais os interesses do mercado de terras do que o bem-estar da população. Barboza (2019, p. 103) também investigou "a hipótese do crescente interesse e jogo político (não oculto) para os deslocamentos compulsórios da população às margens do rio Ururaí, que estaria sendo alimentado pela construção do Loteamento 'Barra de Ururaí' à jusante". O empreendimento, inclusive, aciona "o discurso das 'áreas verdes' e "ambientalmente aprazíveis" justamente nos lugares que antes haviam sido definidos como "de risco". Assim, observou-se uma instrumentalização da noção de risco na própria gestão urbana aliando-se aos interesses do mercado imobiliário (Barboza, 2019).

Foi diante desse cenário que foi realizada, na localidade de Ururaí, uma pesquisa buscando compreender a relação entre os desastres ambientais relacionados à água - como as frequentes inundações que levaram o poder público a classificá-las como "áreas de risco" - e as condições de permanência no lugar, sobretudo a partir da ótica dos moradores sobre o ambiente em que vivem, a percepção sobre as inundações, a noção de risco e os processos de mobilidade por conta das mudanças de residência, objeto específico deste artigo.

Ao reconstruir o processo de chegada da população nas áreas afetadas por inundações na localidade, notou-se que $26 \%$ de famílias declararam ter residido em outros lugares da cidade e ter se mudado para Ururaí, embora a maior parte já residisse no bairro há bastante tempo, conforme aponta a tabela 2. Algumas delas fizeram o último processo de mobilidade residencial no próprio bairro (31\%). E a maior parte sempre morou no mesmo domicílio (37\% das famílias). Se somarmos as famílias que fizeram mobilidade em Ururaí e as que sempre moraram no próprio domicílio, notamos que boa parte da população na área pesquisada é de pessoas que residem ali há bastante tempo (157 famílias correspondendo a 68\% dos 232 domicílios entrevistados), o que sugere uma relação de pertencimento forte com o lugar.

Tabela 2 - Tempo de residência e local de moradia anterior: domicílios em áreas afetadas por inundações em Ururaí (Campos/RJ)

\begin{tabular}{lccccc}
\hline \multirow{2}{*}{$\begin{array}{c}\text { Tempo de residência no } \\
\text { domicílio }\end{array}$} & \multicolumn{3}{c}{ Morou em domicílio anterior } & \\
\cline { 2 - 5 } & $\begin{array}{c}\text { Em outro } \\
\text { bairro ou } \\
\text { cidade }\end{array}$ & $\begin{array}{c}\text { Em } \\
\text { Ururaí } \\
\text { mesmo }\end{array}$ & $\begin{array}{c}\text { Não } \\
\text { morou }\end{array}$ & Não sabe & Total \\
\hline Até 5 anos & $20 \%$ & $39 \%$ & $12 \%$ & $21 \%$ & $23 \%$ \\
\hline Mais de 5 a 10 anos & $5 \%$ & $21 \%$ & $0 \%$ & $7 \%$ & $8 \%$ \\
\hline Mais de 10 a 20 anos & $25 \%$ & $17 \%$ & $13 \%$ & $0 \%$ & $16 \%$ \\
\hline Mais de 20 a 30 anos & $31 \%$ & $11 \%$ & $19 \%$ & $36 \%$ & $21 \%$ \\
\hline Mais de 30 a 40 anos & $11 \%$ & $8 \%$ & $23 \%$ & $7 \%$ & $15 \%$ \\
\hline Mais de 40 anos & $8 \%$ & $3 \%$ & $34 \%$ & $29 \%$ & $17 \%$ \\
\hline Total(100\%) & 61 & 71 & 86 & 14 & 232 \\
\hline & $26 \%$ & $31 \%$ & $37 \%$ & $6 \%$ & $100 \%$ \\
\hline
\end{tabular}

Fonte: NESA/UFF Campos (2015) 
Entre os motivos indicados para a mobilidade residencial na localidade (tabela 3) — os que para lá se mudaram (61 famílias) e os que fizeram a mobilidade interna no bairro (71 famílias) —, a maior parte indicou questões familiares como principal razão (32,6\%). Foram relatadas também dificuldades financeiras ligadas a pagamento de aluguel e busca pela casa própria $(21,2 \%)$. A constituição de nova família/casamento também foi o motivo para cerca de $10 \%$ dos entrevistados. Entre os demais motivos, a referência às inundações (comumente denominadas de "cheias" pelos moradores) foi feita por apenas três entrevistados, assim como estrutura ruim da casa anterior (o que talvez possa ter relação com as inundações também).

Tabela 3 - Motivos para mudança de residência para a localidade: domicílios em áreas afetad as por inund ações em Ururaí (Campos/RJ)

\begin{tabular}{lcc}
\hline \multicolumn{1}{c}{ Motivo para vir para este domicílio } & Frequência & $\begin{array}{c}\text { Porcentagem válida } \\
(\mathbf{\%})\end{array}$ \\
\hline Questões familiares (ficar com fa miliares, separou etc.) & 43 & 32,6 \\
\hline Dificuldades financeira s/pagava aluguel/casa própria & 28 & 21,2 \\
\hline Formação de nova família/casou & 13 & 9,8 \\
\hline Trabalho & 4 & 3 \\
\hline Melhores condições de vida (saúde, educação etc.) & 5 & 3,8 \\
\hline Cheia no local & 3 & 2,3 \\
\hline Independência pessoal & 5 & 3,8 \\
\hline Estrutura ruim na casa anterior & 3 & 2,3 \\
\hline Ganhou a casa/herança & 3 & 2,3 \\
\hline Outros & 7 & 5,3 \\
\hline Não sabe/não lembra/mal especificado & 18 & 13,6 \\
\hline Total & 132 & 100 \\
\hline Fonte: NESA/UFF Campos
\end{tabular}

Fonte: NESA/UFF Campos (2015)

No caso de Ururaí, a problemática definição da propriedade do terreno aliada à proximidade ao rio por parte de muitas residências são marcas desse processo. Nas áreas sujeitas a inundações, abordadas na pesquisa, identificou-se que algumas famílias estão em terrenos que declaram estarem regularizados e possuírem documentação; outras famílias disseram que estão em terrenos e/ou casas cedidos pela antiga Usina Cupim (que teve grande influência na ocupação do espaço na localidade); já outras afirmaram que ocuparam o terreno e tomaram posse; e poucas famílias estão em casas alugadas. Também há situações de muitos domicílios em um mesmo lote e/ou aglomerados.

Portanto, na referida localidade, nota-se que houve impactos da população sobre o ambiente no sentido de ter ocorrido uma ocupação desordenada, muito próxima às margens do rio Ururaí - um processo de mobilidade residencial antigo que afetou sobremaneira o ambiente. Vale notar que, nesse período de maior ocupação, havia um agente de atração: a Usina Cupim, que, inclusive, cedeu terrenos e casas para alguns moradores.

Assim como a ocupação da população no espaço afeta esse ambiente, os eventos ambientais também exercem influência sobre a dinâmica da população. Essa dupla face da relação sociedade e ambiente também se evidencia na localidade de estudo, sobretudo pela ocorrência de desastres como inundações.

A maior parte dos domicílios pesquisados passou por inundação pelo menos uma vez (81,5\%), sendo 50,5\% apenas uma vez; os outros $31 \%$ relataram que o episódio ocorreu mais de uma vez. Alguns domicílios mais próximos ao rio, numa parte do bairro onde os moradores a denominam Ilha, foram afetados muitas vezes. Devido à proximidade, com qualquer transbordo do rio, a água já entra na casa. Algumas famílias $(15,5 \%)$ disseram que nunca 
tiveram a casa afetada; provavelmente, são famílias que residem há menos tempo no domicílio, já que, na inundação de 2008, toda essa área realmente havia sido afetada.

Muitas das famílias entrevistadas nas áreas afetadas tiveram perdas materiais decorrentes dos desastres relacionados à água - 149 famílias correspondendo a 74,5\% dos 200 domicílios que declararam terem sido afetados. Entre as perdas, captadas por meio de pergunta aberta no questionário, a mais citada foi a dos móveis. Em alguns casos, foram mencionados, adicionalmente, elementos como eletrodomésticos, roupas, documentos, alimentos. Além dessas perdas materiais, algumas famílias (11,5\%) descreveram a ocorrência de problemas de saúde devido às enchentes.

No período em que a pesquisa foi realizada, a vivência com a noção de risco era muito forte entre os moradores. A prefeitura fez marcações em várias casas que seriam removidas. Ao serem questionados se acham que "o domicílio está em uma área de risco", 110 entrevistados disseram que sim, e 118 afirmaram que não (quatro não responderam). Sobre o fato de alguém já ter lhes dito que estão em área de risco, as respostas também foram bem divididas, 113 disseram que sim, e 115 falaram que não. Entre os que acham que estão em área de risco, ao serem perguntados sobre o porquê, foi dito que é devido à proximidade com o rio, à experiencia com as inundações ou à estrutura inadequada das casas, como a presença de rachaduras. Já para aqueles que não acham que estão em área de risco, a justificativa que dão para essa percepção é que não foram notificados, como outros vizinhos, que dificilmente a água chega em suas casas ou que a grande enchente ocorreu apenas uma vez, em 2008. Alguns moradores também falaram que o poder público não se empenha em resolver o problema e criar condições para deixar as famílias ali mesmo. Interessante notar que vários moradores também expuseram outros tipos de risco, como "violência, criminalidade, tráfico de drogas" e "a ausência do poder público no bairro".

É interessante observar que, ao cruzarmos as duas perguntas (tabela 4), a maior parte dos que realmente acham que estão em área de risco disseram que foram "notificados" sobre isso por alguém (70\%). Já entre os que não acham que estão em área de risco, a maior parte também disse não ter sido informada a respeito. É possível interpretar que a noção de risco realmente seja produzida socialmente, pois a incorporação do discurso difundido na localidade também pode ser um mecanismo dessa produção social. Ao perguntarmos quem fez tal notificação, a maior parte citou ter sido a Defesa Civil. Outros apontaram ainda assistentes sociais, representantes da prefeitura/supervisor de bairro, além da circulação da informação entre moradores e parentes sobre o que a prefeitura estava fazendo na localidade. Ao mesmo tempo, alguns residentes notificados disseram que não consideram estar em área de risco e que não souberam nada a respeito. Talvez esse possa ser um mecanismo de resistência e de rejeição ao discurso da área de risco.

Tabela 4 - Cruzamento sobre percepção da área de risco e informação sobre risco: domicílios em áreas afetadas por inundações em Ururaí (Campos/RJ)

\begin{tabular}{|c|c|c|c|}
\hline \multirow{2}{*}{$\begin{array}{l}\text { O domicílio está em } \\
\text { uma área de risco? }\end{array}$} & \multicolumn{2}{|c|}{$\begin{array}{l}\text { Alguém já disse que a sua } \\
\text { casa está em área de risco? }\end{array}$} & \multirow{2}{*}{$\begin{array}{c}\text { Total } \\
(\mathbf{1 0 0 \%})\end{array}$} \\
\hline & Sim & Não & \\
\hline Sim & $70 \%$ & $30 \%$ & 110 \\
\hline Não & $30,5 \%$ & $69,5 \%$ & 118 \\
\hline Total & 113 & 115 & 228 \\
\hline
\end{tabular}

Fonte: NESA/UFF Campos (2015)

Sobre a expectativa de mobilidade residencial, para avaliar se pretendem sair da casa ou do bairro, a percepção sobre a possível mudança — embora apresente alguns diferenciais 
— foi bem contundente no sentido de os entrevistad os indicarem que não gostariam de sair do lugar em que residem (tabela 5), pois acreditam que haveria a possibilidade de implementar melhorias na própria localidade. Em relação a sair da casa devido às cheias, 69 entrevistados disseram que sairiam, mas 54\% destes disseram, depois, que não gostariam de deixar o bairro. Já 154 manifestaram que não sairiam devido às cheias, e, destes, 87\% disseram que também não sairiam do bairro. A maior participação é mesmo deste grupo — que não quer sair nem de suas casas nem do bairro de Ururaí - , correspondendo a 77\% dos que responderam a esses quesitos conjuntamente.

É possível notar, portanto, a relação de pertencimento dos moradores com o lugar, mesmo diante das condições relatadas. A incerteza de enfrentar um processo de desenraizamento e de adaptação a uma nova localidade parece ser mais problemática do que o enfrentamento das condições ambientais existentes, até porque muitos moradores relataram que já estão acostumados com as "cheias" e que "sabem se virar" quando o rio começa a encher.

Para os que disseram que têm interesse em mudar de bairro, a maior parte (25) não soube especificar para onde; 12 apenas expressaram que gostariam de ir para algum lugar próximo a Ururaí; outros oito fizeram referência a algum conjunto habitacional; seis entrevistados disseram que iriam para um bairro próximo, a Tapera, que tem um conjunto habitacional do programa Morar Feliz. Outros seis fizeram referência à enchente, dizendo que só não queriam ir para um lugar que tivesse enchente; alguns também citaram bairros que apresentam conjuntos habitacionais ou outras localidades.

Tabela 5 - Pretensão de sair da casa e de mudar de bairro: domicílios em áreas afetadas por inundações em Ururaí (Campos/RJ)

\begin{tabular}{l|r|r|r}
\hline \multirow{2}{*}{$\begin{array}{c}\text { Pretende sair da casa em } \\
\text { função das cheias? }\end{array}$} & \multicolumn{2}{|c|}{$\begin{array}{c}\text { Você gostaria de mudar de } \\
\text { bairro? }\end{array}$} & \multirow{2}{*}{$\begin{array}{c}\text { Total } \\
(\mathbf{1 0 0 \%})\end{array}$} \\
\cline { 2 - 3 } & \multicolumn{1}{|c|}{ Sim } & \multicolumn{1}{c}{ Não } & \\
\hline Sim & $46 \%$ & $54 \%$ & 69 \\
\hline Não & $13 \%$ & $87 \%$ & 154 \\
\hline Total & 52 & 171 & 223 \\
\hline
\end{tabular}

Fonte: NESA/UFF Campos (2015)

Portanto, foi possível notar que, embora a maior parte não queira sair da casa nem do bairro, também há algumas famílias que ainda vivem a expectativa de conseguir uma casa em um conjunto habitacional. No período da pesquisa, várias delas já haviam sido removidas para conjuntos habitacionais, principalmente aquelas mais próximas ao rio Ururaí. Muitas casas haviam sido derrubadas pela prefeitura, e os escombros ainda estavam no lugar. Outras famílias estavam aguardand o o processo de remoção, e outras tantas não queriam sair.

Para apreender a experiência desses sujeitos num espaço de muitas incertezas, foram feitas perguntas sobre os processos de remoção. Entre os entrevistados, 91,4\% conheciam famílias que haviam sido transferidas para conjuntos habitacionais. Quando questionados se achavam que as pessoas que já tinham saído estavam satisfeitas com a mudança, com o processo de mobilidade residencial realizado nessa conjuntura, as opiniões foram diversas. Notou-se que $43 \%$ dos entrevistados achavam que muitas famílias não estavam satisfeitas devido a violência, brigas, conflitos entre facções ou porque não se adaptaram, não se relacionavam com as pessoas do lugar de destino. Muitos disseram que conheciam várias famílias que haviam retornado para Ururaí, e isso também era um indicativo de insatisfação. Porém, alguns (27\%) também acharam que havia uma parte das famílias que estava satisfeita, uma vez não tinham vontade de sair, acharam o bairro bom, experimentaram o fato de ter uma 
casa nova e própria e não pagar aluguel, e ainda porque saíram de uma área de risco. Outros apresentaram respostas variadas no sentido da satisfação, insatisfação ou não se posicionaram. Vale ressaltar também que $23 \%$ não soube ou não quis opinar.

Sendo assim, observou-se que o ambiente também exerce impactos sobre o comportamento da população, visto que os constantes processos de alagamentos e inundações têm provocado intensas mudanças residenciais na localidade de Ururaí, seja por deslocamentos residenciais internos à localidade (como alguns moradores que recebiam o aluguel social à época da pesquisa), seja por deslocamentos forçados fomentados pelo próprio poder público ao definir certas áreas da localidade como áreas de risco, muitas vezes sem diálogo e participação da comunidade nos processos decisórios e na gestão urbana.

\section{CONSIDERAÇÕES FINAIS}

Este artigo buscou ressaltar algumas dimensões sociais e espaciais sobre a relação entre a questão urbana e ambiental, tratando especificamente da relação entre os processos de mobilidade humana (apreendido pela mobilidade residencial) e os desastres ambientais na cidade (apreendido através das inundações). Como visto, há uma série de eventos sociais, econômicos e políticos que antecedem os fenômenos de desastres, ao mesmo tempo que estes também podem desencadear novos eventos e intervenções no espaço, como os processos de mobilid ade por parte da população afetada.

As origens dessa relação estão no rápido processo de urbanização pelo qual passou boa parte das grandes cidades e metrópoles brasileiras, inclusive as cidades do interior dos estados, sobretudo em períodos de crises do trabalho no campo e da produção agrícola regional. Várias cidades se formaram em um contexto de desordem e precariedades e, em decorrência disso e das situações sociais e econômicas adversas, muitas famílias ocuparam áreas em encostas e beiras de rios e lagoas, com condições ambientais desfavoráveis e sem infraestrutura urbana adequada.

No município de Campos dos Goytacazes, as desigualdades sociais e ambientais também se fazem presentes, e o desenvolvimento urbano não foi satisfatoriamente acompanhado por um planejamento e uma gestão territorial que considerassem, inclusive, as condições sociais e ambientais para ocupação das diferentes áreas da cidade. À polaridade regional histórica do município e à sua inserção na dinâmica econômica global sob a lógica do capital financeiro-imobiliário-urbano e a atuação das indústrias extrativas estão associadas intervenções urbanas por meio das políticas habitacionais que refletem um tipo de gestão seletiva, fragmentada e setorial, sem integração com outras políticas sociais e ações (como nas áreas de mobilidade urbana, educação, saúde, infraestrutura etc.), mediante mecanismos autoritários e sem instâncias de participação coletiva.

A localidade de Ururaí onde concentrou-se este estudo é uma expressão de tal fenômeno. Houve um intenso processo de ocupação muito próxima ao rio em Ururaí (Campos/RJ) somando as desigualdades sociais às desigualdades ambientais, fazendo com que, atualmente, além de serem consideradas áreas de pobreza, ou áreas "carentes", acrescente-se à sua qualificação o termo "área de risco". Ou seja, houve um processo passado de mobilidade residencial para a localidade que gerou uma complexa e controversa ocupação do espaço, fazendo com que as inundações estejam relacionadas às práticas humanas, às desigualdades sociais e à degradação ambiental. Mais recentemente, também se observou uma expressiva mobilidade residencial na área, impulsionada, em parte, pelas questões ambientais, em parte, por interesses políticos e econômicos nas disputas por apropriação do espaço. 
Muitas famílias foram removidas para outras áreas da cidade, em alguns casos, bem distantes do local de origem, rompendo os vínculos sociais e espaciais com o lugar, inclusive dificultando o acesso a alguns bens e serviços, como trabalho e estudo.

Portanto, nos processos de ocupação do espaço, muitas vezes, ao acionar o discurso do "risco" e atuar somente após a ocorrência de desastres nas cidades, o poder público desenvolve uma gestão urbana que pode contribuir para ocultar a perspectiva dos desastres ambientais como processos socialmente construídos e dificultar ainda mais a definição do que seja a "situação de risco". Alguns apontamentos deste estudo representam particularidades da localidade e do município tomados para a análise empírica, entretanto, as lógicas que operam na relação sociedade e ambiente estão presentes em muitas cidades brasileiras. Como encaminhamentos de pesquisa, considera-se importante avançar nos estudos que contemplem os diferentes aspectos dessa relação, considerando as distintas escalas e dimensões analíticas. Ter em conta as escalas implica reconhecer as articulações existentes entre processos locais, nacionais e globais. As dimensões analíticas passam pela importância de problematizar as concepções, discursos e ações em torno do risco. Além de trabalhar a construção social do risco a partir da percepção dos próprios sujeitos, também é preciso avançar na identificação das estratégias e ações dos afetados por desastres, a fim de promover instâncias de articulação política que contemplem alternativas às ações de remoção, com a participação da comunidade nos processos decisórios e implementação de políticas integradas nessas áreas.

\section{REFERÊNCIAS}

Acselrad, H. (2009). A duração das cidades: sustentabilidade e risco nas políticas urbanas. Rio de Janeiro: Lamparina.

Almeida, C. V. C. \& Leite, A. F. (2017, outubro). Desenvolvimento de práticas educativas a partir das percepções dos alunos do ensino médio da rede pública de campos dos Goytacazes (RJ) sobre o fenômeno inundação. Anais do Encontro Nacional da ANPEGE, Porto Alegre, RS, Brasil, 12.

Arboleda, M. (2015). Financialization, totality and planetary urbanization in the Chilean Andes. Geoforum, Elsevier BV, 67, 4-13.

Arnall, A. (2019). Resettlement as climate change adaptation: What can be learned from stateled relocation in rural Africa and Asia?. Climate and Development, 11, 253-263.

Azevedo, S., Timóteo, G. M., \& Arruda, A. P. S. N. (2013, outubro). Habitação Social e Segregação Especial: implicações do Programa Municipal "Morar Feliz" em Campos dos Goytacazes. Anais do Encontro Anual da ANPOCS, Caxambu, MG, Brasil, 37.

Barboza, F. M. (2019). Risco para quem? A instrumentalização do "risco" contra o direito à cidade das famílias removidas em Campos dos Goytacazes/RJ. Xxx. Dissertação (Mestrado em Desenvolvimento Regional, Ambiente e Políticas Públicas). Programa de Pós-Graduação em Desenvolvimento Regional, Ambiente e Políticas Públicas, Universidade Federal Fluminense, Campos dos Goytacazes, RJ, Brasil.

Bartholomeu, M. C. (2018, dezembro). As delimitações da unidade regional entre Rio de Janeiro (RJ) e São Paulo (SP): da megalópole à megarregião. Anais do Congresso Observatório das Metrópoles 20 Anos, Rio de Janeiro, RJ, Brasil, 1. 
Beltramino, T. (2018). Naturaleza, riesgo y sociedad. La construcción social de las inundaciones en Santa Fe (1982-83/2003). Pampa Revista Interuniversitaria de Estudios Territoriales, 14 (17), 31-54.

Brandão, C. (2007). Território e Desenvolvimento: as múltiplas escalas entre o local e o global. Campinas: Editora da Unicamp.

Ministério do Desenvolvimento Regional. Sistema Integrado de Informações sobre Desastre- S2ID. Recuperado em 01 out. 2009, de: <https://s2id.mi.gov.br/paginas/sobre.xhtml〉.

Carmo, R. L. (2014). Urbanização e Desastres: Desafios para a segurança humana no Brasil. In R. L. Carmo, \& N. Valencio (Orgs), Segurança humana no contexto dos Desastres (pp. 114). Campinas: RiMa.

Cruz, J. L. V. (2003). Projetos nacionais, elites locais e regionalismo: desenvolvimento e dinâmica territorial no Norte Fluminense. 331. Tese (Doutorado em Planejamento Urbano e Regional). Programa de Pós-Graduação em Planejamento Urbano e Regional, Universidade Federal do Rio de Janeiro, Rio de Janeiro, RJ, Brasil.

Cruz, J. L. V. \& Terra, D. (2020). Petróleo e porto no norte do estado do Rio de Janeiro, Brasil. EURE, 46 (139), 189-208.

Deschamps, M. (2008). Estudo sobre a vulnerabilidade socioambiental na região metropolitana de Curitiba. Cadernos Metrópole, 19, 191-219.

Douglas, M. \& Wildavsky, A. (2012). Risco e cultura. Um ensaio sobre a seleção de riscos tecnológicos e ambientais. Rio de Janeiro: Elsevier.

Fragoso, M. L. C. \& Silva, T. A. A. (2019). Desastre, risco e vulnerabilidade urbana: uma análise a partir das enchentes e inundações no município de Escada/PE. Revista Cadernos de Ciências Sociais, 14 (1), 36-53.

GUIVANT, J. S. (1998). A Trajetória das Análises de Risco: da Periferia ao Centro da Teoria Social. Revista Brasileira de Informações Bibliográficas, 46, 3-38.

Hogan, D. J. (2005). Mobilidade populacional, sustentabilidade ambiental e vulnerabilidade social. Revista Brasileira de Estudos Populacionais, 22 (2), 323-338.

Instituto Brasileiro de Geografia e Estatística (2010). Sinopse do Censo Demográfico de 2010. Rio de Janeiro, IBGE. Janeiro: IBGE. . (2016). Arranjos populacionais e concentrações urbanas do Brasil (2a ed.). Rio de . IBGE Cidades. Recuperado em 30 jul. 2021, de: <https://cidades.ibge.gov.br>. Instituto Igarapé. Observatório de migrações forçadas. Recuperado em 01 out. 2020, de: $<$ https://migracoes.igarape.org.br>. 
Lencioni, S. (2015). Urbanização difusa e a constituição de megarregiões: o caso de São Paulo-Rio de Janeiro. E-metropolis: Revista Eletrônica de Estudos Urbanos e Regionais, 6, 615.

Leopoldo, E. (2018, dezembro). A megalópole contemporânea no capitalismo metropolitanofinanceiro: mercado de capitais e financeirização imobiliária na megarregião Rio de JaneiroSão Paulo. Anais do Congresso Observatório das Metrópoles 20 Anos, Rio de Janeiro, RJ, Brasil, 1.

Marandola Jr., E. \& Dal Gallo, P. M. (2010). Ser migrante: implicações territoriais e existenciais da migração. Revista Brasileira de Estudos Populacionais, 27 (2), 407-424.

Marandola Jr., E. (2014). Habitar em risco: mobilidade e vulnerabilidade na experiência metropolitana. São Paulo: Blucher.

Maricato, E. (2002). As ideias fora do lugar e o lugar fora das ideias. Planejamento urbano no Brasil. In O. Arantes, C. Vainer, \& E. Maricato. A cidade do pensamento único. Desmanchando consensos (pp. 121-192). Petrópolis: Editora Vozes.

Marter-Kenyon, J. (2020). Origins and functions of climate-related relocation: An analytical review. The Anthropocene Review, 7 (2), 159-188.

Mendes, J. T. N. (2015). O ato de habitar a partir de um programa habitacional. In A. M. M. Siqueira, N. Valencio, M. Siena, \& M. Malagoli (Orgs.), Riscos de desastres relacionados à água. Aplicabilidade de bases conceituais das Ciências Humanas e Sociais para a análise de casos concretos (pp. 141-160). São Carlos: RiMa.

Menezes, M. A. (2012). Migrações e mobilidades: repensando teorias, tipologias e conceitos. In: P. E. Teixeira, A. M. C. Braga, \& R. Baeninger (Orgs.), Migrações: implicações passadas, presentes e futuras (pp. 21-40). Marília: Oficina Universitária; São Paulo: Cultura Acadêmica.

Piquet, R. (2010). O Norte Fluminense em Tempo Presente. In A. M. S. P. Santos, G. J. Marafon, \& M. J. G. Sant'ana (Orgs.), Rio de Janeiro: Um olhar socioespacial (pp. 79-100). Rio de Janeiro: Gramma.

Quarantelli, E. L. (2015). Uma agenda de pesquisa do século 21 em ciências sociais para os desastres: questões teóricas, metodológicas e empíricas, e suas implementações no campo profissional. O Social em Questão, 33, 25-56.

Quiñonez, I. T. N., Saavedra, G. A. D., Cevallos, J. J. M. \& Jiménez, M. B. Espacio urbano periférico y la construcción social del riesgo en ciudades intermedias. Cuadernos de Vivienda y Urbanismo, 13, 1-18.

Ribeiro, L. C. Q. (2008). Para onde vão as cidades brasileiras? In J. P. R. Velloso (Org.), $O$ Amor em Tempos de Desamor e o Enigma: o Brasil Tem Jeito? (pp. 150-190). Rio de Janeiro: José Olympio. 
Silva, E. T. (2012). Estrutura urbana e mobilidade espacial nas metrópoles. Rio de Janeiro: Letra capital.

Silva, A. O., Séllos-Knoerr, V. C. de, Janes, D. dos S., \& Martins, J. A. M. (2020). Preparing Structured Abstract as an Instrument in Scientific Dissemination: Guidelines. International Journal of Professional Business Review, 5(2), IV-XII. https://doi.org/10.26668/businessreview/2020.v5i2.215

Siqueira, A. M. M. \& Malagodi, M. A. S. (2013). Desastres e remoções em Campos dos Goytacazes, RJ: o caso de Ururaí. In A. F. Leite, \& M. Gomes (Orgs.), Dinâmica ambiental e produção do espaço urbano e regional no Norte Fluminense (pp. 35-66). Campos dos Goytacazes: Essentia.

Siqueira, A. M. M., Valencio, N., Siena, M. \& Malagodi, M. (Orgs.) (2015). Riscos de desastres relacionados à água. Aplicabilidade de bases conceituais das Ciências Humanas e Sociais para a análise de casos concretos. São Carlos: RiMa.

Swyngedouw, E. \& Heynen, N. (2003). Urban political ecology, justice and the politics of scale. Antipode, 35(5), 888-918.

Tavares, E. \& Firmo, C. P. (2018, setembro). Desigualdades socioambientais e trajetórias escolares: perspectivas de jovens estudantes em Campos dos Goytacazes/RJ. Anais do Encontro Nacional de Estudos Populacionais da ABEP, Poços de Caldas, MG, Brasil, 1.

Torres, P. H., Ramos, R. F. \& Sanches, G. L. (2018, setembro). Questão ambiental e megarregião: o caso da macrometrópole paulista. Anais do Congresso Observatório das Metrópoles 20 Anos, Rio de Janeiro, RJ, Brasil, 1.

Urry, J. (2007). Mobilities. Cambridge: Polity.

Vainer, C. V. (2000). Estado e Migrações no Brasil: anotações para uma história das políticas migratórias. Revista Travessia, 36, 15-32.

Valencio, N. (2009). Da morte da Quimera à procura de Pigaso: a importância da interpretação sociológica na análise do fenômeno denominado desastre. In N. Valencio, M. Siena, V. Marchezini, \& J. Gonçalves (Orgs), Sociologia dos Desastres: construções, interfaces e perspectivas no Brasil (pp. 3-18). São Carlos: RiMa.

Soares, P. P. M. A. \& Cruz, S. H. R. (2019). A Ecologia Política das inundações urbanas na Bacia do Una em Belém (PA). Emancipação, 19 (1), 1-15.

Valencio, N. (2012). Para além do "dia do desastre”: o caso brasileiro. Curitiba: Appris. 